\title{
The anesthetic management of ventricular septal defect (VSD) repair in a child with mitochondrial cytopathy
}

\author{
[La démarche anesthésique adoptée pendant la réparation d'une communication \\ interventriculaire (CIV) chez une enfant présentant une cytopathie mitochondriale]
}

Ehab Farag MD FRCA, Maged Argalious MD, Samer Narouze MD, Glenn E. DeBoer MD, Julie Tome MD

Purpose: To present the anesthetic management for the correction of a ventricular septal defect (VSD) in a patient with multiple acyl CoA dehydrogenase deficiency (glutaric aciduria type II; GAll). A review of the literature about anesthetic management of patients with mitochondrial diseases undergoing cardiopulmonary bypass (CPB) is also included.

Clinical features: An I I-yr-old girl with GAll manifested as severe hypoglycemia since she was a newborn and generalized muscle weakness. She underwent open-heart surgery for VSD correction with CPB. The anesthetic management avoided inhalational anesthetics, maintained the blood sugar within normal limits and continued normothermia during CPB in order to avoid the stress of hypothermia for her abnormal mitochondria. The patient tolerated the procedure well and experienced a good recovery.

Conclusion: The anesthetic management of patients with any mitochondrial disease requires normoglycemia, normothermia and the avoidance of metabolic stress in order to preserve energy production by the diseased mitochondria.

Objectif : Présenter la démarche anesthésique adoptée pour la correction d'une communication interventriculaire (CIV) chez une enfant souffrant de déficience multiple d'acyl-CoA déshydrogénase (acidurie glutarique de type II ; AGII). Nous incluons également une revue de la prise en charge anesthésique de patients atteints de maladies mitochondriales qui subissent une circulation extracorporelle (CEC).

Éléments cliniques : Une enfant de II ans, atteinte d'AGll, présentait une hypoglycémie sévère depuis sa naissance et une faiblesse musculaire généralisée. Elle a subi une opération à cœur ouvert pour la correction d'une CIV sous CEC. Nous avons évité les anesthésiques d'inhalation, maintenu la glycémie dans les limites de la normale et poursuivi la normothermie pendant la CEC afin d'éviter le stress de l'hypothermie sur les anomalies mitochondriales. La patiente a bien toléré l'intervention et connu une bonne récupération.

Conclusion : L'anesthésie de patients atteints de maladie mitochondriale exige une normoglycémie, une normothermie et l'absence de stress dans le but de préserver la production d'énergie par les mitochondries lésées.

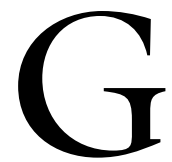

LUTARIC aciduria type II (GAII) is one type of mitochondrial cytopathy that affects $B$-oxidation of fatty acids. In this form of mitochondrial disease, glucose is utilized as the sole source of energy. Thus during metabolic stress (i.e., fasting), severe hypoglycemia and nonketotic metabolic acidosis result. There are very few actual reports but many anecdotal stories of poor postanesthesia outcomes in patients with mitochondrial diseases. This is a case report of a child with GAII in which general anesthesia and normothermic cardiopulmonary bypass (CPB) were used for the correction of a ventricular septal defect.

\section{Case report}

An 11-yr-old girl weighing $50 \mathrm{~kg}$ presented for elective closure of a perimembranous ventricular septal defect (VSD). The patient was diagnosed with GAII at seven months of age. Symptoms of her mitochondrial cytopathy were worsening, and included "metabolic episodes" which consisted of frontal and occipital migraine headaches accompanied by diplopia and vomiting. These "episodes" were treated with glucose

From Sections of Pediatrics and Congenital Heart Disease Anesthesia, The Cleveland Clinic Foundation, Cleveland, Ohio, USA. Address correspondence to: Dr. Julie Tome, Staff Anesthesiologist, The Cleveland Clinic Foundation, Division of Anesthesia and Critical Care Medicine, 9500 Euclid Ave., Cleveland, OH 44195, USA. Phone: 216-444-8389; Fax: 216-445-2536; E-mail: TOMEJ@CCF.ORG Accepted for publication March 22, 2002.

Revision accepted July 22, 2002. 
infusions and dexamethasone. Due to severe hypoglycemia $\left(<1.9 \mathrm{mmol} \cdot \mathrm{L}^{-1}\right)$, the patient received routine overnight enteral feedings via a percutaneous endoscopic gastrostomy tube to maintain normal blood glucose level and to avoid development of hypoglycemia. The urgent need for permanent intravascular access for parenteral nutrition and metabolic management was anticipated. The presence of VSD (though hemodynamically insignificant) was considered to be a major risk factor for endocarditis and possible air embolism.

\section{Patient's past medical history}

She was born at 33 weeks gestation with a VSD and atrial septal defect (ASD). At seven days of age, she had a cardiac arrest at home and was diagnosed with severe apnea and a seizure disorder. A failure to thrive investigation at seven months included a skin biopsy and fibroblast culture, which were consistent with GAII. She remained on an apnea monitor until 18 months, at which time her ASD had closed spontaneously. The patient became progressively more symptomatic with gastric dysmotility, asthma and proximal muscle weakness often requiring wheelchair use by the age of nine years. Mental status and intelligence were normal for age. The family history was significant in that her mother, brother, and maternal aunts were all diagnosed with mitochondrial disorders. Echocardiography showed normal left ventricle function and size and a small perimembranous VSD with left to right flow maximum velocity of $4.7 \mathrm{~m} \cdot \mathrm{sec}^{-1}$. No other abnormalities were detected. Her intolerance to lorazepam resulted in severe agitation.

\section{Anesthetic management}

During preoperative fast, the patient received $10 \%$ dextrose in $0.25 \%$ normal saline infusions at 90 $\mathrm{mL} \cdot \mathrm{hr}^{-1}$. After routine monitors were applied, induction of anesthesia was managed with ketamine $50 \mathrm{mg}$ $\left(1 \mathrm{mg} \cdot \mathrm{kg}^{-1}\right)$ and fentanyl $100 \mu \mathrm{g}\left(2 \mu \mathrm{g} \cdot \mathrm{kg}^{-1}\right)$; intubation was facilitated with rocuronium $25 \mathrm{mg}(0.5$ $\left.\mathrm{mg} \cdot \mathrm{kg}^{-1}\right)$. A 20 gauge arterial catheter was inserted into the left radial artery and a central venous pressure line (CVP) into the right internal jugular vein. Anesthesia was maintained with $\mathrm{N}_{2} \mathrm{O}$ in $\mathrm{O}_{2}$ in preCPB period then with $100 \% \mathrm{O}_{2}$ after bypass period with intermittent doses of ketamine (total $150 \mathrm{mg}$ ) to prevent awareness and rocuronium was titrated to train-of-four (TOF) response. Analgesia was provided by a remifentanyl infusion at the dose of 0.2 $\mu \mathrm{g} \cdot \mathrm{kg}^{-1} \cdot \mathrm{min}^{-1}$ and a morphine infusion at 40 $\mu \mathrm{g} \cdot \mathrm{kg}^{-1} \cdot \mathrm{hr}^{-1}$. Body core temperature was maintained between $35.9^{\circ} \mathrm{C}$ and $36.4^{\circ} \mathrm{C}$ throughout the proce- dure and during CPB. Serum blood glucose was 5 $\mathrm{mmol} \cdot \mathrm{L}^{-1}$ after anesthetic induction with a lactate level of $1.3 \mathrm{mmol} \cdot \mathrm{L}^{-1}$. During $\mathrm{CPB}$ serum blood sugar was in the $10-12.9 \mathrm{mmol} \cdot \mathrm{L}^{-1}$ range and serum lactate level peaked at $2.6 \mathrm{mmol} \cdot \mathrm{L}^{-1}$ (normal up to $2.0 \mathrm{mmol} \cdot \mathrm{L}^{-1}$ ) measured immediately post-CPB. Total bypass time was $33 \mathrm{~min}$ and aortic cross-clamp time was $11 \mathrm{~min}$. The CPB pump was primed with a solution containing dexamethasone in the dose of $0.25 \mathrm{mg} \cdot \mathrm{kg}^{-1}$, plasmalyte, $25 \%$ albumin, $\mathrm{NaHCO}_{3}$ and calcium chloride. The pump flow was kept at $100-128 \mathrm{~mL} \cdot \mathrm{kg}^{-1} \cdot \mathrm{min}^{-1}$ to maintain a cardiac index of $2.4 \mathrm{~L} \cdot \mathrm{m}^{2} \cdot \mathrm{min}^{-1}$ and venous oxyhemoglobin saturation was between $75-80 \%$. Closure of the VSD was confirmed by a transesophageal echocardiography contrast study. Central venous pressure was maintained post-bypass at 6 $\mathrm{mmHg}$ with boluses of $0.9 \%$ normal saline as needed. During recovery, insulin was administered to keep blood glucose at $10-12 \mathrm{mmol} \cdot \mathrm{L}^{-1}$. Sodium nitroprusside $1.5 \mu \mathrm{g} \cdot \mathrm{kg}^{-1} \cdot \mathrm{min}^{-1}$ was administered for two hours postoperatively to control blood pressure. She was transfused to a hematocrit of $30 \%$ after $\mathrm{CPB}$ with pump blood. The postoperative course was uneventful and the patient was discharged from the hospital on the third day.

The child denied awareness and discomfort during the procedure, and family or caretakers have denied any increase in muscle weakness or other neurologic disturbances. Her medications on discharge were the same as preoperatively: Coenzyme Q10, Vitamin B, carnitine, amitriptyline, and paroxetine.

\section{Discussion}

Mitochondrial cytopathies can be divided into two main categories. In the first category, the respiratory complexes in the respiratory chain are affected as in MELAS and Kearns-Sayre syndromes. ${ }^{1-4}$ In the second category, lipid metabolism is affected either due to a defect in the transferred fatty acids across the mitochondrial membrane which is caused by carnitine deficiency or due to a defect of B-oxidation of fatty acids. In both cases, the energy production from lipid metabolism will be insufficient. ${ }^{1}$

GAII was first described by Przyrembel in 1976 as a deficiency in the electron transfer flavoprotein (ETF) that moves electrons from flavine-adenine dineclotide (FAD) of acyl CoA dehydrogenases to coenzyme Q in the respiratory chain. This leads to the accumulation of free fatty acids in the plasma and the urinary excretion of large amounts of organic acids. This condition differs from glutaric aciduria type 1 , characterized by the accumulation of glutaric acid, which is due to a recessively inherited deficiency of glutaryl CoA dehydrogenase. . $^{5-8}$ 
GAII has been categorized into three subgroups. The first group is the neonatal onset GAII that includes congenital anomalies such as dysmorphic facies (potter type), polycystic kidneys and other general abnormalities. The second group is the neonatal onset GAII without congenital abnormalities, which presents immediately after birth or in the first days of neonatal life. The patients usually have symptoms of respiratory distress, hypoglycemia and metabolic acidosis without ketosis. The third group is the late onset GAII which is characterized by repeated episodes of hypoglycemia accompanied by elevated serum concentrations of free fatty acids without ketosis, fatty infiltration of the liver, hepatic dysfunction and proximal myopathy. This disease is usually characterized by a "generalized sweaty foot odour." The urine of these patients contains increased amounts of organic acids such as glutaric acid, ethylmalonic acid and dicarboxylic acids with six to ten carbons. The hypoglycemia is due to impaired oxidation of fatty acids resulting in decreased hepatic gluconeogenesis. The increased amounts of glutaryl CoA and ethylmalonic acid lead to the inhibition of mitochondrial uptake of malate, which is a rate-limiting step in gluconeogenesis. ${ }^{9}$ GAII is usually accompanied by lactic acidosis, which arises from a severe energy deficiency in the muscle and from an impaired recycling of lactate to glucose via the Cori cycle. ${ }^{9}$ The acidosis leads to impaired renal excretion of uric acid resulting in hyperuricemia. ${ }^{9}$ Riboflavin which acts as the precursor of FAD which is the common coenzyme of acyl CoA dehydrogenase, can be used as a treatment for GAII exacerbations. ${ }^{10}$

There is no single scheme or method to follow for the anesthetic management of patients with mitochondrial cytopathies. By reviewing the literature, every agent and technique have been used successfully, however, there are certain controversial issues that should be considered. ${ }^{4,11}$ Volatile anesthetics have been used uneventfully in several case reports. ${ }^{12,13}$ However, in one case report a malignant hyperthermia type episode occurred when inhalation anesthetics and succinylcholine were used. $^{14}$ In our case, potent inhalational anesthetics were avoided due to the fear of lactic acidosis and the inability to distinguish postbypass hyper metabolic states from anesthesia-induced malignant hyperpyrexia. Additionally, myocardial depressant effects can be caused by volatile anesthetics due to reductions in intracellular calcium concentration, and inhibition of the sodium-calcium exchange mechanism. Recently it has been shown that halothane and sevoflurane have inhibitory effects upon norepinephrine-induced glucose uptake in neonatal cardiomyocytes. This decrease in glucose uptake is associated with lowered intracellular calcium and diminished myocardial contractility. Glucose represents the sole energy supply to the newborn heart in contrast to the adult heart, which depends mainly upon fatty acids as a source of energy. ${ }^{15}$ This finding emphasizes the importance of avoiding hypoglycemia in pediatric patients in order to avoid myocardial depression. This is especially important when dealing with children who have impaired glucose homeostasis and are unable to utilize fatty acids as in the child presented in this report. In spite of the age of the patient, the myocardial cells can still be immature due to mitochondrial disease. It has been documented that the mitochondrial cytopathies in general can be accompanied by cardiomyopathy, ${ }^{16,17}$ however, fortunately, our patient has normal cardiac function. One of the sites of action of inhalation anesthetics is the gas- 1 (general anesthetic sensitive) gene, which encodes $49-\mathrm{KDa}$ (IP) subunit of complex 1 of the respiratory chain. The proteins $49-\mathrm{KDa}$ (IP) are essential for the proper function of complex 1 of the respiratory chain. The volatile anesthetics inhibit gas- 1 gene and decrease the function of complex $1^{18}$ thus enhancing the inhibitory effects of volatile anesthetics in the patients with mitochondrial diseases. $\mathrm{N}_{2} \mathrm{O}$ in vitro increases $\mathrm{NO}$ and is known to inhibit cis-acotinase and iron containing electron transport enzymes and may also affect energy production. ${ }^{4}$ However, we chose to use $\mathrm{N}_{2} \mathrm{O}$ to reduce the risk of awareness, in lieu of benzodiazepines. In order to maintain metabolic homeostasis in our patient, Ringer's lactate was avoided to prevent an exacerbation of lactic acidosis. Instead, dextrose $10 \%$ in $0.25 \%$ normal saline was titrated to serum glucose levels of $10-12 \mathrm{mmol} \cdot \mathrm{L}^{-1}$. Third space losses were replaced with a normal saline infusion.

The use of hypothermic CPB (to $28^{\circ} \mathrm{C}$ ) has been reported in a patient with mitochondrial disease. ${ }^{19}$ The 41-yr-old patient with Kearns-Sayre syndrome underwent hypothermic $\mathrm{CPB}$ for aortic coarctation repair, aortic valve repair and patent ductus arteriosus ligation. However, a normothermic $\mathrm{CPB}$ technique was used in our patient to achieve many goals. Liver function and hepatic mitochondrial redox potentials are measured by arterial ketone body ratio (AKBR) and hepatic venous ketone body ratio, which is usually calculated by the ratio of acetoacetate to 3 -hydroxybutarate. This potential is better maintained with normothermic CPB than with hypothermic CPB. The complement system activity and the immune system are better maintained with normothermic $\mathrm{CPB}$ due to a better AKBR thus decreasing the production of immune mediators during $\mathrm{CPB}$ and inflammatory processes as well. Also with low hepatic mitochondrial activity, phagocytosis by Kupffer cells and the retic- 
uloendothelial system activity decline which increases in the incidence of postoperative infections. ${ }^{20,21}$ In this case, AKBR was not measured, however, lactic acid level was measured as a global index of anaerobic metabolism. Also, during hypothermic $\mathrm{CPB}$ the increase of free radical potential is high due to increased tissue $\mathrm{PaO}_{2}$ levels, which can have a deleterious effect upon cellular functions especially in patients with mitochondrial disease. ${ }^{22}$ Because mitochondria uses oxidative metabolism to produce energy to achieve and maintain normothermia in the early postoperative period, we felt that compulsive maintenance of core and surface body temperatures during $\mathrm{CPB}$ and the post-CPB periods were essential to avoid further metabolic stress in this patient.

Although it has been reported that patients with mitochondrial cytopathies may have decreased ventilatory response to hypoxia and hypercarbia, ${ }^{23,24}$ this did not occur in the present case. Vigilant monitoring of respiratory function should be maintained post major surgery in an intensive care unit. Muscle relaxants are often avoided in mitochondrial cytopathy patients due to reports of prolonged recovery times. ${ }^{25,26} \mathrm{We}$ chose intermittent doses of rocuronium for lack of its cardiovascular effects and intermediate duration. The relaxation was adequate and the patient did not show impaired neuromuscular function, with a complete recovery time of less than one hour after the last dose.

\section{Conclusion}

We report the anesthetic management of a pediatric patient with a mitochondrial cytopathy, GAII undergoing normothermic $\mathrm{CPB}$. Maintaining normothermia, normoglycemia and avoiding metabolic stress are important issues in perioperative management. Our patient had a successful outcome from this procedure. Parents, caretakers, surgeons, pediatric intensivists and treating pediatricians must all be aware of the issues involved with the care of patients with mitochondrial cytopathies and prepare for untoward metabolic and neurologic complications.

\section{Acknowledgement}

We thank Dr. Emad Mossad, Head Section of Anesthesia for congenital heart disease at The Cleveland Clinic Foundation, for his help and advice in preparing this manuscript.

\section{References}

1 Miller JD, Rosenbaum H. Muscle diseases. In:

Benumof JL (Ed.). Anesthesia and Uncommon Diseases, $4^{\text {th }}$ ed. Philadelphia, PA: WB Saunders, 1998: $351-4$.
2 Petty RKH, Harding AE, Morgan-Hughes JA. The clinical features of mitochondrial myopathy. Brain 1986; 109: 915-38.

3 Wallace JJ, Perndt H, Skinner M. Anaesthesia and mitochondrial disease. Paediatr Anaesth 1998; 8: 249-54.

4 Farag E, Barsoum S, Spagnuolo S, Tetzlaff JE. Anesthesia and muscle disease. Am J Anesthesiol 2000; 27: 491-501.

5 Mooy PD, Przyrembel H, Giesberts MAH, Scholte HR, Blom W, van Gelderen HH. Glutaric aciduria type II: treatment with riboflavine, carnitine and insulin. Eur J Pediatr 1984; 143: 92-5.

6 Sweetman L, Nyban WL, Tranner DA, Merritt TA, Singh M. Glutaric aciduria type II. J Pediatr 1980; 96: 1020-6.

7 Goodman SI, Frerman FE. Glutaric acidaemia type II (multiple acyl-CoA dehydrogenation deficiency). J Inherit Metab Dis 1984; 7(Suppl 1): 33-7.

8 Gregersen N, Kolvraa S, Rasmussen $K$, et al. Biochemical studies in a patient with defects in the metabolism of acyl-CoA and sarcosine: another possible case of glutaric aciduria type II. J Inherit Metab Dis 1980; 3: 67-72.

9 Dusheiko G, Kew MC, Joffe BI, Lewin JR, Mantagos S, Tanaka $K$. Recurrent hypoglycemia associated with glutaric aciduria type II in an adult. N Engl J Med 1979; 301: 1405-9.

10 Harpey JP, Charpentier C, Goodman SI, Darbois $\Upsilon$, Lefebvre G, Sebbah J. Multiple acyl-CoA dehydrogenase deficiency occurring in pregnancy and caused by a defect in riboflavin metabolism in the mother. Study of a kindred with seven deaths in infancy: value of riboflavin therapy in preventing this syndrome. J Pediatr 1983: 103: 394-8.

11 Maslow A, Lisbon A. Anesthetic considerations in patients with mitochondrial dysfunction. Anesth Analg 1993; 76: 884-6.

12 Lauwers $M H$, Van Lersberghe C, Camu F. Inhalation anesthesia and the Kearns-Sayre syndrome. Anaesthesia 1994; 49: 876-8.

13 Burns AM, Shelly MP. Anaesthesia for patients with mitochondrial myopathy. Anaesthesia 1989; 44: 975-7.

14 Obtani Y, Miike T, Ishitsu T, Matsuda I, Tamari H. A case of malignant hyperthermia with mitochondrial dysfunction (Letter). Brain Dev 1985; 7: 249.

15 Kudoh A, Matsuki A. Halothane and sevoflurane decrease norepinephrine-stimulated glucose transport in neonatal cardiomyocyte. Anesth Analg 2000; 91: 1151-9.

16 Marin-Garcia J, Goldenthal MJ. Mitochondrial cardiomyopathy. Pediatr Cardiol 1995; 16: 28-30.

17 Channer KS, Channer JL, Campbell MJ, Russell Rees J. 
Cardiomyophathy in the Kearns-Sayre syndrome. Br

Heart J 1988; 59: 486-90.

18 Kayser E-B, Morgan PG, Sedensky MM. GAS-1: a mitochondrial protein controls sensitivity to volatile anesthetics in the nematode caenorhabditis elegans. Anesthesiology 1999; 90: 545-54.

19 Pivalizza EG, Ando KJ, Sweeney MS. Kearns-Sayre syndrome and cardiac anesthesia. J Cardiothorac Vasc Anesth 1995; 9: 189-91.

20 Hashimoto K, Sasaki T, Hachiya T, et al. Superior hepatic mitochondrial oxidation-reduction state in normothermic cardiopulmonary bypass. J Thorac Cardiovasc Surg 2001; 121: 1179-86.

21 Nomoto S, Shimabara $\Upsilon$, Kumada K, Okamoto $\Upsilon$, Ban $T$. Influence of hepatic mitochondrial redox state on complement biosynthesis and activation during and after cardiopulmonary bypass operations. Eur J Cardiothorac Surg 1996; 10: 273-8.

22 Gaillard D, Bical O, Paumier D, Trivin F. A review of myocardial normothermia: its theoretical basis and the potential clinical benefits in cardiac surgery. Cardiovasc Surg 2000; 8: 198-203.

23 Barohn RJ, Clanton T, Sabenk Z, Mendell JR.

Recurrent respiratory insufficiency and depressed ventilatory drive complicating mitochondrial myopathies. Neurology 1990; 40: 103-6.

24 Kitoh T, Mizuno K, Otagiri T, Ichinose A, Sasao JI, Goto $H$. Anesthetic management for a patient with Kearns-Sayre syndrome. Anesth Analg 1995; 80: 1240-2.

25 Robertson JA. Ocular muscular dystrophy. A cause of curare sensitivity. Anaesthesia 1984; 39: 251-3.

26 Naguib M, El Dawlatly AA, Ashour M, Al-Bunyan M. Sensitivity to mivacurium in a patient with mitochondrial myopathy. Anesthesiology 1996; 84: 1506-9. 